\title{
A Profibrotic Phenotype in Naive and in Fibrotic Lung Myofibroblasts Is Governed by Modulations in Thy-1 Expression and Activation
}

\author{
Pazit Y. Cohen, ${ }^{1}$ Raphael Breuer, ${ }^{1,2}$ and Shulamit B. Wallach-Dayan ${ }^{1}{ }^{1}$ \\ ${ }^{1}$ Lung Cellular and Molecular Biology Laboratory, Institute of Pulmonary Medicine, Hebrew University Hadassah Medical School, \\ 91120 Jerusalem, Israel \\ ${ }^{2}$ Department of Pathology, Boston University School of Medicine, Boston, MA 02118, USA
}

Correspondence should be addressed to Shulamit B. Wallach-Dayan; wallach-dayan@hadassah.org.il

Received 18 December 2017; Revised 5 March 2018; Accepted 12 April 2018; Published 29 May 2018

Academic Editor: Mirella Giovarelli

Copyright ( 2018 Pazit Y. Cohen et al. This is an open access article distributed under the Creative Commons Attribution License, which permits unrestricted use, distribution, and reproduction in any medium, provided the original work is properly cited.

Lung fibrosis is characterized by abnormal accumulation of Thy-deficient fibroblasts in the interstitium of the alveolar space. We have previously shown in bleomycin-treated chimeric Thyl-deficient mice with wild-type lymphocytes that Thyl-deficient fibroblasts accumulate and promote fibrosis and an "inflammation-free" environment. Here, we aimed to identify the critical effects of Thy1, or the absence of Thy1, in lung myofibroblast profibrotic functions, particularly proliferation and collagen deposition. Using specific Thy1 siRNA in Thy1-positive cells, Thy1 knockout cells, Thy1 cDNA expression vector in Thy1deficient cells, and Thyl cross-linking, we evaluated cell proliferation (assessed by cell mass and BrdU uptake), differentiation (using immunofluorescence), and collagen deposition (using Sircol assay). We found that myofibroblast Thy1 cross-linking and genetic manipulation modulate cell proliferation and expression of Fgf (fibroblast growth factor) and Angtl (angiotensin) receptors (using qPCR) that are involved in myofibroblast proliferation, differentiation, and collagen deposition. In conclusion, lung myofibroblast downregulation of Thyl expression is critical to increase proliferation, differentiation, and collagen deposition.

\section{Introduction}

Pulmonary fibrosis is characterized by abnormal accumulation of myofibroblasts in the interstitium and alveolar space $[1,2]$. Persistent myofibroblast survival and accumulation are the essential events underlying the evolution of lung fibrosis in animal models and idiopathic pulmonary fibrosis (IPF) in humans [3].

Several mechanisms have been suggested to drive the unabated multiplication of myofibroblasts in IPF [4], including a high proliferation rate $[5,6]$ and resistance to apoptosis [7-9], based on evidence from in vitro studies using myofibroblasts from humans with IPF, as well as in vivo research using murine models of lung fibrosis.

Fibroblasts are heterogeneous, differing in phenotype and function $[10,11]$. In the lungs of mice and humans, there are two subpopulations of fibroblasts, which are distinguished by their expression of Thy1 $[10,12]$. It has been shown that fibroblasts in the lungs of humans with IPF and of bleomycin-treated mice are predominantly Thy $1^{-}$[13-16].

Thyl is a $25-37 \mathrm{kDa}$ glycosylphosphatidylinositol(GPI-) anchored cell surface protein that belongs to the immunoglobulin-like gene superfamily [17]. Thy1 has a variety of functions in different tissues [18], including a role in cell apoptosis [19-24] and proliferation [16, 25-31]. It has been reported to function in T cell activation, neurite outgrowth, apoptosis, tumor suppression, and wound healing and fibrosis [32] via multiple pathways. It is involved in T cell activation, and its role in $\mathrm{T}$ cell function has been extensively reviewed [33-35]. In mice and in humans, Thy $1^{+}$and Thy $1^{-}$fibroblasts differ with respect to cytokine $[28,36-39]$ and growth factor responses [40,41], as well as cell migration [42].

Using gene chip analysis, we found that myofibroblast Thy1 cross-linking mediates downregulation of genes 


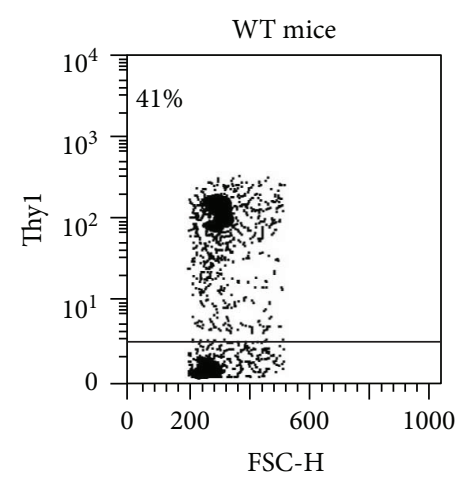

(a)

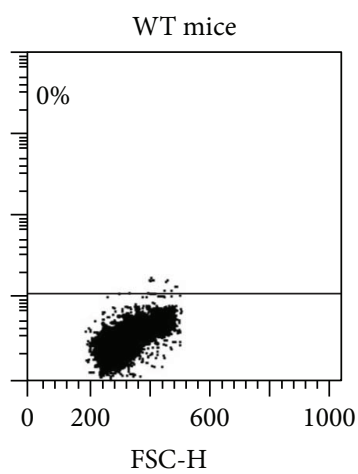

FSC-H

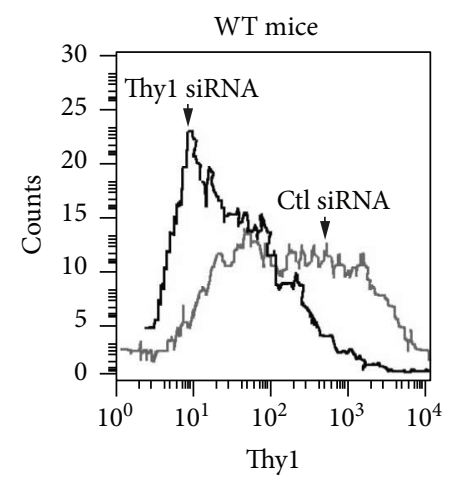

(b)
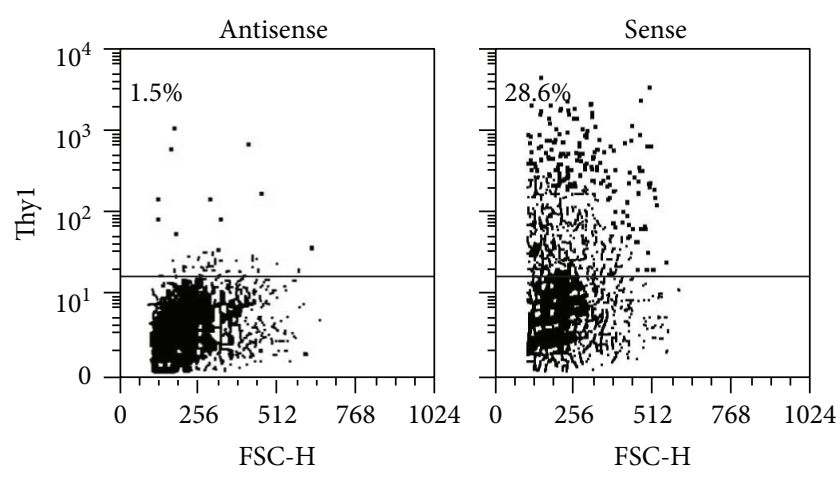

(c)

Figure 1: Thy1 gene expression following genetic manipulation, using Thy1 knockout mice, Thy1 siRNA, and Thy1 cDNA expression vector. (a) Flow cytometry Thy-FITC mAb staining in spleen cells from wild-type (WT) C57BL/6 mice and Thy1-deficient mice, respectively. (b) Downregulation of Thy1 by siRNA was performed. Thy1 downregulation was detected $48 \mathrm{~h}$ after transfection by FACS analysis (c) Mlg cells were transfected with Thyl expression vector. Plasmid-containing Thyl cDNA in antisense orientation serves as a control. Thy1 expression was detected $24 \mathrm{~h}$ after the transfection by FACS analysis.

promoting cell proliferation, survival, and differentiation and reduces production of extracellular matrix (ECM) components, while concurrently mediating the upregulation of genes known to foster inflammation and immunological functions [15].

In the current study, we further evaluated the critical role of Thyl protein in lung myofibroblast proliferation and apoptosis in naïve cells and during the evolution of lung fibrosis, as well as its association with profibrotic functions such as differentiation and collagen production.

\section{Materials and Methods}

2.1. Animals. Male, 11-12-week-old, C57BL/6J mice (Jackson Laboratory, Bar Harbor, ME, USA) and C57BL/6J Thy1deficient mice were used (kindly provided by Professor R.J. Morris, Department of Chemistry, King's College, London, UK). Their Thyl-deficient status versus wild-type (WT) was confirmed in C57BL/6 Thy1-deficient mice by flow cytometry of spleen cells using anti-Thy1-FITC mAb (Figure 1(a)). At 12-14 weeks, body weight for the two types was similar, in the range of 23-27 gm. Histological sections of the lung, heart, brain, colon, liver, and kidney were studied. There were no differences in the histological sections or in lung hydroxyproline content, which were $1274 \pm 181$ (mean \pm SE) and $1122 \pm 73$ in Thyl-deficient and WT controls, respectively. Bronchoalveolar cellularity was also similar in terms of the number of cells per ml, with $99 \%$ macrophages and $1 \%$ lymphocytes or neutrophils. The two groups of mice were thus similar in all respects except for Thyl expression.

All animal procedures were approved by the Hebrew University Hadassah Medical School Animal Care Committee. Mice were housed in a specific pathogen-free environment.

2.2. Intratracheal Instillation. Mice were anesthetized by intraperitoneal (IP) injection of $0.05-0.07 \mathrm{ml}$ of $40 \mathrm{mg} / \mathrm{ml}$ Ketalar (Parke-Davis, Pontypool, Gwent, UK) and $0.5 \mathrm{mg} /$ $\mathrm{ml}$ droperidol (Janssen Pharmaceutica, Beerse, Belgium). A dose of 0.06-0.08 units of bleomycin (H. Lundbeck, Copenhagen, Denmark) dissolved in $0.1 \mathrm{ml}$ of saline solution to induce lung fibrosis, or $0.1 \mathrm{ml}$ of saline alone as control, was slowly injected intratracheally (IT). The mice were sacrificed 14 days after IT, as we have previously described and detailed [3].

2.3. Lung Cell Isolation and Culture and Quantification of Myofibroblasts. The lungs were removed, minced, and incubated $\left(37^{\circ} \mathrm{C}, 5 \% \mathrm{CO}_{2}\right.$ air) for $45 \mathrm{~min}$ in $\mathrm{PBS}$ containing $1 \mathrm{mg} / \mathrm{ml}$ collagenase (C0130, Sigma-Aldrich, St. Louis, MO, 
USA). After enzyme treatment, lung tissue was gently passed through a cell dissociation sieve (Sigma-Aldrich) or $40 \mu \mathrm{m}$ nylon mesh filters (Falcon, Becton Dickinson, Franklin Lakes, NJ) and then washed twice in PBS. For myofibroblast culture experiments, lung cells (LC) were resuspended in fibroblast culture medium. Cell cultures were incubated at $37^{\circ} \mathrm{C}$ in $5 \%$ humidified $\mathrm{CO}_{2}$. Typically, within 1 week of culture initiation, more than $95 \%$ of the cells were morphologically myofibroblasts.

Cells were passaged every 5 days by dissociating monolayers with a mild trypsin solution (Biological Industries, Beit HaEmek, Israel). After initial cultures were established, myofibroblasts obtained on passages 2 through 20 were used. Myofibroblast $\alpha$-SMA cell markers were evaluated by assessment of any increase in cell staining visualized on confocal microscope and by quantification of mean fluorescence intensity (MFI) with flow cytometry using specific anti- $\alpha$ SMA mAb (Dako, Glostrup, Denmark) diluted 1:200 in $1 \%$ BSA.

\subsection{Thy $1^{+}$and Thy $1^{-}$Myofibroblast Subpopulation Sorting by} Flow Cytometry. Myofibroblasts $\left(0.5 \times 10^{6}\right)$ were collected from cultures and incubated in FACS buffer (3\% FCS in PBS) with anti-Thy1.2 PE (Pharmingen, San Diego, CA, USA) $\left(0.06 \mu \mathrm{g}\right.$ per $0.5 \times 10^{6}$ cells $)$ for $30 \mathrm{~min}$ at room temperature, washed with FACS buffer, and analyzed by flow cytometry or sorted using a FACS cell sorter under sterile conditions using a FACS-Star ${ }^{\mathrm{TM}}$ (Beckton-Dickinson, Franklin Lakes, NJ, USA), as shown in (Figure 1(a)). Thy $1^{+}$cells are more spindle-shaped and have more elongated processes than Thy $1^{-}$cells, which are more rounded.

\subsection{Proliferation}

2.5.1. Cell Cycle Analysis by Flow Cytometry. BrdU (SigmaAldrich) was added to the fibroblast culture to reach a final concentration of $20 \mu \mathrm{M}$. The cells were later removed by incubation with trypsin for $2 \mathrm{~h}$ (for Mlg cells) or $6 \mathrm{~h}$ (for primary fibroblasts) and centrifuged at $1200 \mathrm{rpm}$ for $10 \mathrm{~min}$. The pellets were washed in $5 \mathrm{ml}$ of $1 \times$ cold PBS, gently resuspended in $100 \mu \mathrm{l}$ of cold PBS, and fixed by slowly dripping $5 \mathrm{ml}$ of ice-cold ethanol (70\%). Cells were incubated at $-20^{\circ} \mathrm{C}$ for at least $30 \mathrm{~min}$ or overnight, pelleted by centrifugation at $1800 \mathrm{rpm}$ for $5 \mathrm{~min}$, and $1 \mathrm{ml}$ of $2 \mathrm{~N} \mathrm{HCl} /$ Triton X-100 was slowly added with a gentle vortex. Cells were then incubated at room temperature for $30 \mathrm{~min}$, pelleted by centrifugation at $1800 \mathrm{rpm}$ for $5 \mathrm{~min}$, and resuspended in $1 \mathrm{ml}$ of $0.1 \mathrm{M} \mathrm{Na} \mathrm{B}_{4} \mathrm{O}_{7}, \mathrm{pH} 8.5$ to neutralize the sample. After centrifugation $(1800 \mathrm{rpm}$, $5 \mathrm{~min}$ ), the pellet was incubated with $20 \mu \mathrm{l}$ FITCconjugated anti-BrdU (Becton Dickinson) for $30 \mathrm{~min}$ at room temperature. Cells were pelleted and resuspended in $1 \mathrm{ml}$ of PBS containing $5 \mu \mathrm{g} / \mathrm{ml}$ propidium iodide (PI) and stored in the dark until analyzed by flow cytometry. The proliferation distribution was determined by measuring corresponding BrdU uptake versus total DNA content (cells in S phase).

2.5.2. Proliferation Rate Analysis by Confocal Microscope. Myofibroblasts isolated from the mouse lungs were seeded $\left(0.1 \times 10^{6}\right)$ on $22 \times 22 \mathrm{~mm}$ glass coverslips in fibroblast culture medium. After $24 \mathrm{~h}, \mathrm{BrdU}$ was added to the culture to a final concentration of $20 \mu \mathrm{M}$. Nonadherent cells were removed $6 \mathrm{~h}$ later, and adherent cells were washed twice with PBS and fixed by incubation with cold $70 \%$ ethanol overnight at $20^{\circ} \mathrm{C}$. Cells were then incubated with $0.5 \mathrm{ml}$ of $2 \mathrm{~N}$ $\mathrm{HCl} /$ Triton $\mathrm{X}-100$ (room temperature, $30 \mathrm{~min}$ ), and $0.5 \mathrm{ml}$ of $0.1 \mathrm{M} \mathrm{Na} \mathrm{B}_{4} \mathrm{O}_{7}, \mathrm{pH} 8.5$ was added. Cells were then washed with PBS and incubated with $20 \mu \mathrm{l}$ anti-BrdUFITC (Becton Dickinson) for $30 \mathrm{~min}$ at room temperature. PI $5 \mu \mathrm{g} / \mathrm{ml}$ was added for $2 \mathrm{~min}$. Cells were then washed twice with PBS, and coverslips were mounted on glass microscope slides with mounting solution and examined with a confocal microscope (Carl Zeiss AG, Oberkochen, Germany) attached to a Zeiss Axiovert 135M inverted microscope.

2.5.3. Cell Growth Assessment by Methylene Blue Staining. The growth of myofibroblast monolayers was assessed by colorimetric quantitation of the cell mass of the surviving monolayer after staining with the basic dye methylene blue [43]. Assays were initiated with $10^{4}$ cells/well in 96-well microtiters, plated, and incubated overnight to confluence at $37^{\circ} \mathrm{C}$ in a $5 \% \mathrm{CO}_{2}$ environment. Cells were fixed in $2.5 \%$ glutaraldehyde in $200 \mu \mathrm{l}$ of medium. Fixed monolayers were washed twice with $200 \mu \mathrm{l}$ of borate buffer $(10 \mathrm{mM}, \mathrm{pH} 8.4)$ and stained for $1 \mathrm{~h}$ with methylene blue (1\% in $10 \mathrm{mM}$ borate buffer). Excess stain was removed by three washes with double-distilled water (DDW), and plates were dried overnight at room temperature. Bound methylene blue was extracted with $200 \mu \mathrm{l}$ of $0.1 \mathrm{M} \mathrm{HCl}$ followed by $1 \mathrm{~h}$ incubation at $37^{\circ} \mathrm{C}$ and measured at an optical density of $620 \mathrm{~nm}$ in a microtiter plate reader (Titertek Multiskan MMC, Flow Laboratories, Irvine, UK).

2.5.4. Cell Proliferation Assessment by CFSE Staining. In order to track myofibroblast growth, the cells were stained by fluorescent carboxyfluorescein diacetate succinimidyl ester (CFSE) [44] to allow flow cytometry visualization of eight to 10 discrete generations of cell division both in vitro and in vivo. CFSE labeling is distributed equally between daughter cells after division. Daughter cells thus show half of the fluorescence of their parent cells.

$2 \times 10^{6}$ myofibroblasts $/ \mathrm{ml}$ were resuspended in PBS. An equal volume of freshly diluted $2.5 \mu \mathrm{M}$ CFSE (Molecular Probes) in PBS was added for $8 \mathrm{~min}$ at room temperature and staining was stopped by the addition of an $1 \mathrm{ml}$ icecold FCS for $1 \mathrm{~min}$. Cells were immediately washed three times in RPMI 1640, and the cells were cultured for $72 \mathrm{~h}$. The intensity of CFSE labeling was measured by flow cytometry with CFSE intensity labeling at time 0 serving as a control measurement.

2.6. Myofibroblast Thy1 Activation. Subconfluent myofibroblasts were stimulated with anti-Thy1 G7, which has previously been shown to activate $\mathrm{T}$ cells [45], or with anti-rat IgG2C $\kappa$ isotype control (Pharmingen). We followed the methods discussed previously by Cohen et al. [46]. Both stimulants were added to myofibroblasts at varying 
concentrations ranging from $1-20 \mu \mathrm{g} / \mathrm{ml}$, together with recombinant protein $G$ cross-linker (Sigma-Aldrich) at the same concentration.

\subsection{RNA}

2.7.1. RNA Isolation. Total cellular RNA was isolated from myofibroblasts in culture using TRI Reagent (cat. number T9424, Sigma-Aldrich) according to the protocol supplied by the manufacturer. To assess RNA integrity and exclude DNA contamination, an aliquot of each sample was analyzed by electrophoresis on a $1 \%$ agarose stained with ethidium bromide. Purity and quantitation of RNA was assessed by spectrophotometer.

2.7.2. Reverse Transcription Polymerase Chain Reaction (RT-PCR). RNA was reverse transcribed to cDNA using an avian myeloblastosis virus RT-based protocol and random primers, as well as poly-dT (Reverse Transcription System, Promega, Madison, WI, USA). One microgram of each sample was uniformly used for reverse transcription. The cDNA was diluted in a final volume of $200 \mu \mathrm{l}$ with nuclease-free water.

TaqMan real-time PCR, primers, and probes were purchased from Applied Biosystems (Foster City, CA, USA). Probe sequences of the genes analyzed were as follows:

(i) $18 \mathrm{~s} 5^{\prime}$-ATTGGAGGGCAAGTCTGGTGCCAGC-3'

(ii) FGFR 5 '-GCTCGGCACGAGACAGACTGGTCTTA-3'

(iii) AGRT1 $5^{\prime}$-TTTCGCCAAGCCTGCACCTCCATGC-3'

The real-time PCR reaction mixture contained 9 or $4.5 \mu \mathrm{l}$ of the sample and 10 or $5 \mu \mathrm{l}$ of $2 \times$ TaqMan Universal PCR Master Mix (Applied Biosystems), 1 or $0.5 \mu \mathrm{l}$ of $20 \times$ mix of unlabeled PCR primers, and a fluorogenic probe $\left(5^{\prime} \mathrm{FAM}\right.$ dye labeled). A PRISM 7000 Sequence Detection System (Applied Biosystems) was used with the default thermal cycling program $\left(95^{\circ} \mathrm{C}\right.$ for $10 \mathrm{~min}$ followed by 40 cycles of $95^{\circ} \mathrm{C}, 20$ seconds, $60^{\circ} \mathrm{C}$, and 1 minute). Reactions were performed in triplicate. The relative quantification method was used with $\Delta \mathrm{Ct}$ calculated as $\mathrm{Ct}$ (target gene)-Ct (18s gene). The relative quantity of the product was expressed according to the formula $2^{-\Delta \mathrm{Ct}}$.

2.8. Construction of Thy1 Expression Vector. Thy1 expression vector was obtained by ligation of the entire Thy1 cDNA into pTARGET ${ }^{\mathrm{TM}}$ mammalian expression vector (Promega). Thy1 cDNA was generated from primary culture of mouse lung fibroblasts by RT-PCR, using two specific primers assigned from the published above in the paragraph discussing RT-PCR.

(i)Forward- 5' GACAAGCTTATGAACCCAGCCAT3'

(ii)Reverse- 5'GCCTCTAGATCACAGAGAAATGAA3'

The PCR product of the expected size, coded for the full-length cDNA of Thy1, was purified using Wizard SV Gel and PCR Clean-Up System (Promega, Madison, WI, USA) according to the manufacturer's instructions. Purified products were cloned into a pTARGET mammalian expression vector (Promega), according to manufacturer's instructions. The correctness of the insert was confirmed by sequencing (Danyel Biotech, Mira Korner, Hebrew University, Jerusalem, Israel).

\subsection{Gene Expression Manipulation}

2.9.1. Downregulation of Gene Expression by siRNA. SiRNAs were purchased from Qiagen (Valencia, CA, USA). Nontargeting siRNA (cat. number SI1027281) was used as a control.

2.9.2. Thy1 Downregulation. A combination of two types of Thy1 siRNA, 10 picomole of each (cat. numbers SI01448132 and SI01448125), was used.

2.9.3. Transfection Using the DreamFect ${ }^{\mathrm{TM}}$ Kit. $1 \mu \mathrm{g}$ of expression vector was delivered into cultured fibroblasts $(0.25 \times 106)$ in each well of a 6 -well plate, in the presence of $4 \mu \mathrm{l} / 1 \mu \mathrm{g}$ DNA DreamFect (OZ Biosciences, Marseille, France), to $2 \mathrm{ml}$ final medium volume. Following incubation at $37^{\circ} \mathrm{C}$ in humidified $95 \%$ air, $5 \% \mathrm{CO}_{2}$ atmosphere, the medium was renewed.

2.9.4. Transfection Using Electroporation. Myofibroblasts were harvested and washed twice with ice-cold phosphatebuffered saline (PBS) $\left(\mathrm{Mg}^{2+}, \mathrm{Ca}^{2+}\right.$ free) and resuspended in solution $\mathrm{R}$ (transfection kit). Small interference RNA (siRNA) or cDNA expression vector $(2 \mu \mathrm{g})$ was added to $12 \mu \mathrm{l}$ of cell suspension containing $0.5 \times 106$ cells. The mixture was then subjected to a single pulse from a micoporator apparatus (Digital Bio Technology, Seoul, South Korea). After shocking, samples were added to growth medium with $10 \%$ FCS. Protein expression analysis was performed $24-48 \mathrm{~h}$ after transfection.

2.9.5. Exogenic Thy1 Gene Expression Manipulation Using Thy1 siRNA or Thy1 cDNA Expression Vector. Transfected fibroblasts were tested to detect changes in Thyl expression by staining with anti-Thyl antibody and flow cytometry analysis. Thyl downregulation was detected when siRNA specific to Thy1 was introduced into primary myofibroblasts isolated from the mouse lungs, with mean fluorescence intensity (MFI) of Thyl staining decreasing from 553 to 83 (Figure 1(b)). Thy1 upregulation was detected when Thy1 expression vector was introduced into Mlg cell line (mouse lung-transformed fibroblasts) that lacks Thy1 expression. Expression of Thy1 was accomplished in $28.6 \%$ of nonThy1 expressor Mlg cell line (mouse lung fibroblast), using sense but not antisense/control orientation of Thyl cDNA (Figure 1(c)).

2.10. Statistical Analysis. The Mann-Whitney nonparametric test was performed for comparison of two groups. $p<0.05$ was considered statistically significant.

\section{Results and Discussion}

3.1. Thy1 Expression and Myofibroblast Proliferation. Thy1 expression is associated either with a low or a high rate of cell growth in different cell types [16, 25, 26, 28-31]. Since we found an increase in the proportion of Thy $1^{-}$myofibroblasts among the total myofibroblast population at day 14 following bleomycin IT [15], we assessed whether the high rate of lung 


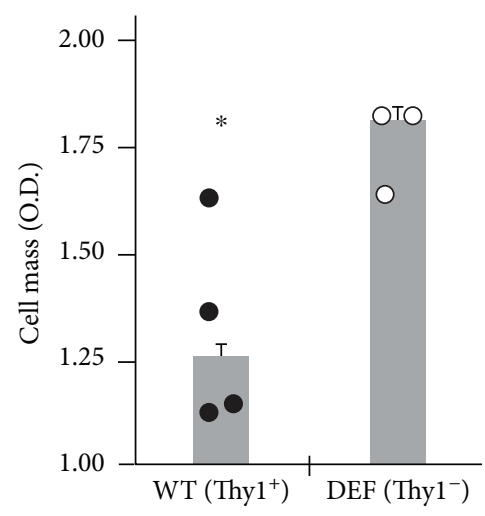

(a)

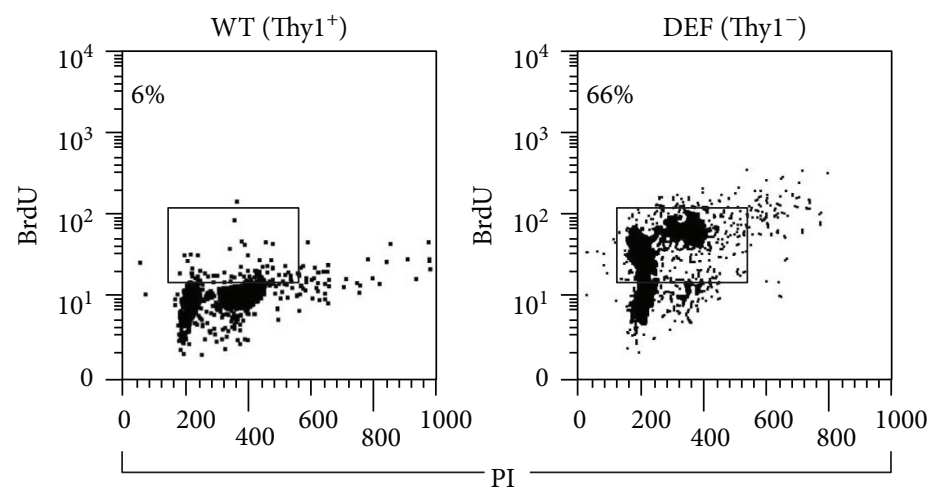

(b)

FIgURE 2: Proliferation of myofibroblasts from WT- and Thy1-deficient (DEF) mice. (a) Cell mass of myofibroblasts isolated from WT and Thy1 (DEF) mice measured after $24 \mathrm{~h}$ by methylene blue staining, followed by colorimetric assay. The results are presented as fold change from day $0\left(n=3-4\right.$ in each group) $\left({ }^{*} p<0.05\right)$. (b) BrdU uptake in myofibroblasts from WT (Thy $\left.1^{+}\right)$and Thy1 (DEF) mice (Thy $\left.1^{-}\right)$ previously treated with $10 \mu \mathrm{M}$ BrdU for $24 \mathrm{~h}$. BrdU uptake was assessed by anti-BrdU-FITC-conjugated mAb staining versus PI-total DNA staining followed by flow cytometry.

myofibroblast proliferation is associated with an absence of Thy1 expression. To this end, myofibroblasts were isolated from the lungs of Thyl-deficient and WT-untreated mice. Results show a high proliferation rate as detected by cell mass measurement in myofibroblasts isolated from Thy1deficient mice compared to myofibroblasts isolated from WT mice (Figure 2(a)). These results were confirmed by cell cycle analysis and BrdU uptake showing higher percentage of proliferation in myofibroblasts isolated from Thy1-deficient mice (66\%) compared to myofibroblasts isolated from WT mice (6\%) (Figure 2(b)).

3.2. Inverse Correlation between Thy1 Expression and Fibroblast Proliferation. We then assessed whether the variance in proliferation rates between $\mathrm{Thyl}^{+}$and $\mathrm{Thyl}^{-}$ myofibroblasts can be attributed to differences in Thyl expression. A Thy1-negative lung fibroblast cell line, Mlg, was transfected with a Thy1.2 expression vector or a control with antisense orientation. Proliferation was assessed following transfection, by cell mass measurement and BrdU uptake. As shown, introduction of Thyl cDNA expression vector into the Mlg cell line decreased its proliferation rate as measured by cell mass, from 1.8 (O.D.) in the control vector-transfected cells to 1.35 in Thy1-upregulated Mlg cells (Figure 3(a)). These results were confirmed by cell cycle analysis, which showed a decrease in the proliferation rate of Thy1-upregulated Mlg cells to 16\% compared to $26 \%$ for control Thy ${ }^{-}$cells (Figure 3(b)).

Concomitantly, by knocking down Thyl expression in murine primary lung myofibroblasts $\left(\mathrm{Thy}^{+}\right.$) using specific siRNA, we demonstrated that the myofibroblast proliferation rates were increased, as assessed by cell mass measurements, from 1.1 to 1.5 (O.D.) in Thyl-downregulated myofibroblasts (Figure 3(c)). These results were further confirmed by cell cycle analysis with BrdU uptake showing concomitant increases in proliferation rates for myofibroblasts with downregulated Thy1 (39.4\%) compared to control (17.8\%) (Figure 3(d)).

3.3. Thy1 Activation Downregulates Expression of Several Genes That Have a Role in Lung Fibroblast Proliferation. As we have previously shown [15], gene chip analysis revealed that Thy1 activation downregulated the expression of several genes that have a role in lung fibroblast proliferation [46], including genes affecting the cell cycle, as well as genes involved in signaling in the MAPK [47], insulin [48, 49], and TGF $\beta[50,51]$ pathways. In this study, we validated these gene chip results by real-time RT-PCR. We chose to validate fibroblast growth factor receptor (FGFR1) [52] and angiotensin receptor (AGRT1) [53], which appear to have important roles in fibroblast proliferation. Results obtained by real-time RT-PCR were consistent with gene chip analysis, which showed decreases in expression of both genes (Figures 4(a) and $4(\mathrm{~b})$, resp.). This downregulation may provide some explanation for our observation that Thy1 expression attenuates lung myofibroblast proliferation due to the decrease in myofibroblast receptors that transmit proproliferation signals.

3.4. Thy $1^{-}$Myofibroblasts from the Fibrotic Lungs Are More Proliferative Than Thy $1^{+}$Myofibroblasts. In order to extend the in vitro findings performed in naïve cells (Figures 1-4) to the in vivo murine model of lung fibrosis, we compared the proliferation of Thy $1^{+}$and Thy $1^{-}$myofibroblasts isolated from the fibrotic lungs. Myofibroblasts were isolated from the lungs of bleomycin-treated mice and sorted into Thy $1^{+}$and Thy $1^{-}$by FACS cell sorter. As shown in Figure 5, the proliferation rate increased from 0.68 to $0.9 \mathrm{OD}$ when assessed by cell mass measurement (Figure 5(a)) and from 54.8\% to $89 \%$ based on CFSE staining (Figure 5(b)). The BrdU uptake rate (Figure 5(c), yellow spots) was higher for Thy1 $1^{-}$myofibroblasts compared with Thy $1^{+}$myofibroblasts. 


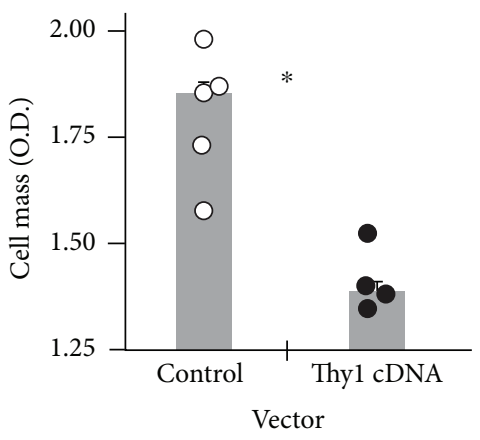

(a)

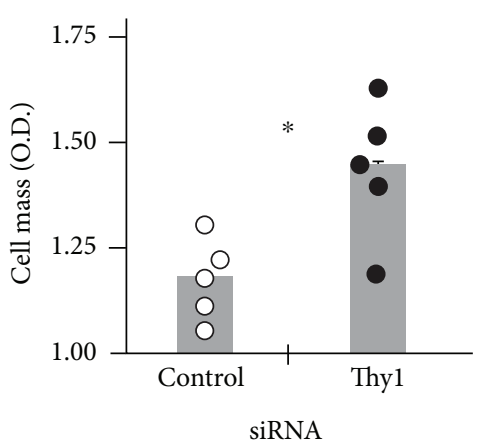

(c)
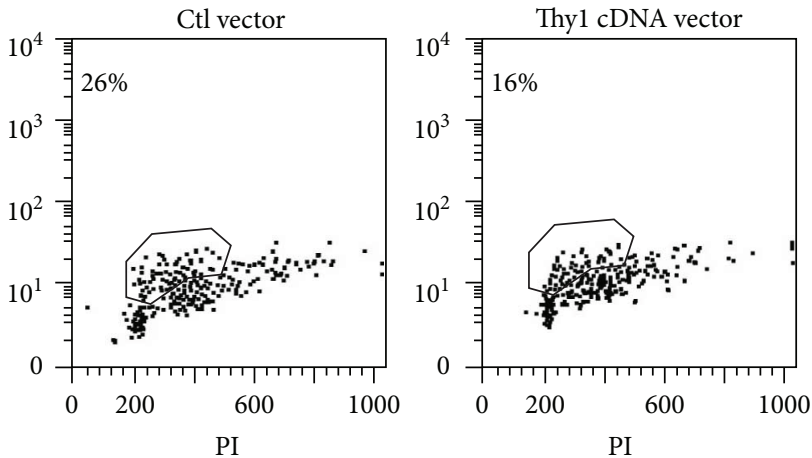

(b)
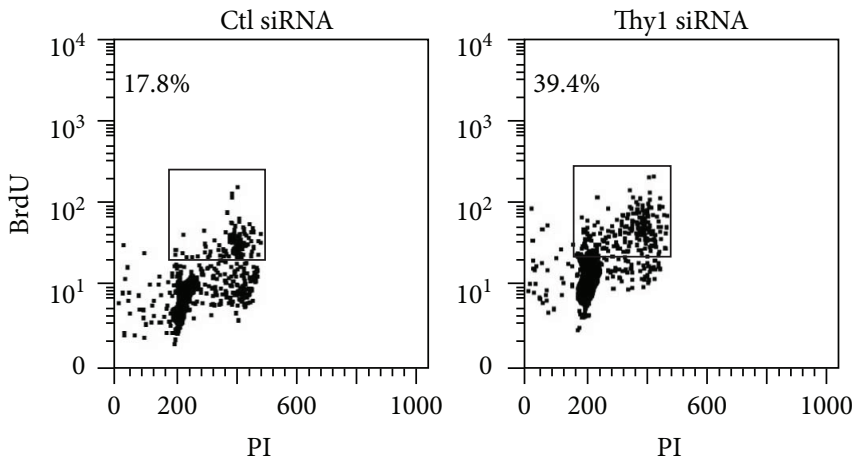

(d)

FIGURE 3: Inverse correlation between Thyl expression and fibroblast proliferation. (a) $24 \mathrm{~h}$ following transfection, cell mass was measured by colorimetric assay using methylene blue staining in Mlg cells transfected with Thy1 expression vector and in control plasmid-containing Thy1 cDNA in antisense orientation. Results are presented as fold change from day $0\left(n=4-5\right.$ in each group) $\left({ }^{*} p<0.05\right)$. (b) BrdU uptake in Mlgtransfected cells with Thy1 expression vector or control plasmid-containing Thy $1 \mathrm{cDNA}$ in antisense orientation following treatment with $20 \mu \mathrm{M}$ BrdU for $2 \mathrm{~h}$. BrdU uptake was assessed by anti-BrdU-FITC-conjugated mAb staining versus PI-total DNA staining followed by flow cytometry analysis. (c) In primary lung myofibroblasts transfected with nontargeting siRNA (Ctl) or Thyl siRNA, cell mass was measured by colorimetric assay after methylene blue staining, $24 \mathrm{~h}$ posttransfection. Results are presented as fold change from day 0 . In each group, $n=5,{ }^{*} p<0.05$. (d) BrdU uptake in primary lung myofibroblasts transfected with nontargeting siRNA (Ctl) or Thyl siRNA, following transfection and treatment with $20 \mu \mathrm{M}$ BrdU for $6 \mathrm{~h}$. BrdU uptake was assessed by flow cytometry analysis, following antiBrdU-FITC-conjugated mAb staining versus PI-total DNA staining.

3.5. Thy1 Expression Is Not Involved in the Regulation of Myofibroblast Apoptosis. In addition to increased proliferation, myofibroblast accumulation in lung fibrosis can also result from their decreased capability to undergo apoptosis. We initially assessed whether Thyl has a role in determining basal levels of lung fibroblast apoptosis. To this end, cleavage of pro-caspase 3 was assessed in Thy $1^{+}$and Thy $1^{-}$fibroblasts taken from the lungs of bleomycin-treated mice.

Cleavage was also assessed in a lung fibroblast cell line (Mlg), following transfection with a Thy 1.2 expression vector or a control vector, and in murine primary lung myofibroblasts transfected with Thyl siRNA or control siRNA. Repeat experiments showed no cleavage of the pro-caspase 3 in any of the tested fibroblasts (Figure 6(a)), indicating that Thy 1 expression does not have a role in the regulation of basal fibroblast apoptosis.

In order to assess the requirement of Thyl activation, as opposed to just Thyl expression in the regulation of fibroblast apoptosis, we followed the methods described in Cohen et al. [46]. Briefly, primary lung myofibroblasts were stimulated with G7 anti-Thyl mAb $(10 \mu \mathrm{g} / \mathrm{ml})$, which we have previously shown to induce Src phosphorylation [46]. Cleavage of pro-caspase 3 and DNA ladders was determined in primary fibroblasts following Thy1 activation. No procaspase 3 cleavage or DNA ladders were observed following Thyl activation (Figures 6(b) and 6(c), resp.), further confirming that Thyl does not influence apoptosis.

3.6. Induction of Myofibroblast Differentiation Is Associated with Downregulation of Thy1 Expression. Myofibroblasts are activated fibroblasts expressing $\alpha$-smooth muscle actin protein $(\alpha$-SMA), and are the major cellular component in IPF fibroblastic foci [54]. The origin of these myofibroblasts is controversial. Some studies suggest that they derive from preexisting peribronchial and perivascular adventitial fibroblasts [55] while others suggest that they result from fibroblasts that have been induced to differentiate into myofibroblasts by treatment with cytokines, such as TGF $\beta$ [56, 57], which is known to be secreted [39] and activated [41] following exposure to fibrotic stimuli. It has been 


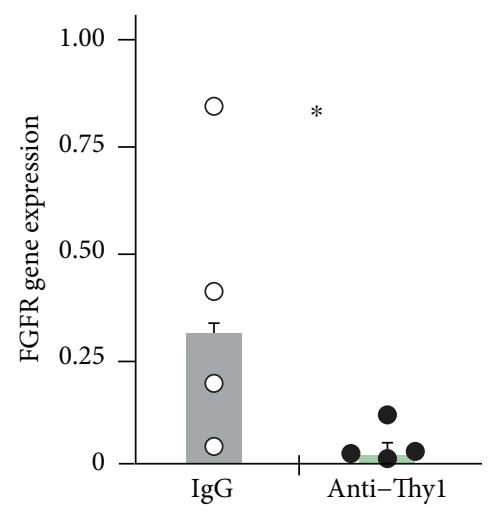

(a)

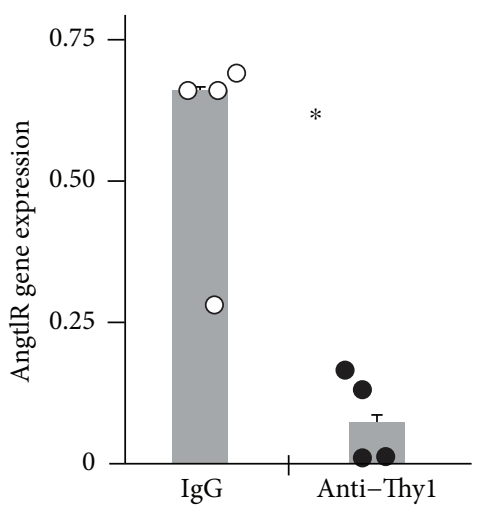

(b)

FIGURE 4: FGFR and AGRT1 mRNA expressions are decreased following Thy1 activation. Primary fibroblasts stimulated with G7 anti-Thy1 $\mathrm{mAb}(10 \mu \mathrm{g} / \mathrm{ml})$ or control IgG isotype for $30 \mathrm{~min}$ (for FGFR) or $1 \mathrm{~h}$ (for AGRT1). Gene expression was detected by real-time RT-PCR $\left({ }^{*} p<0.05\right)$. (a) Relative expression of FGFR mRNA normalized to $18 \mathrm{~s}$. (b) Relative expression of AGRT1 mRNA normalized to $18 \mathrm{~s}$.

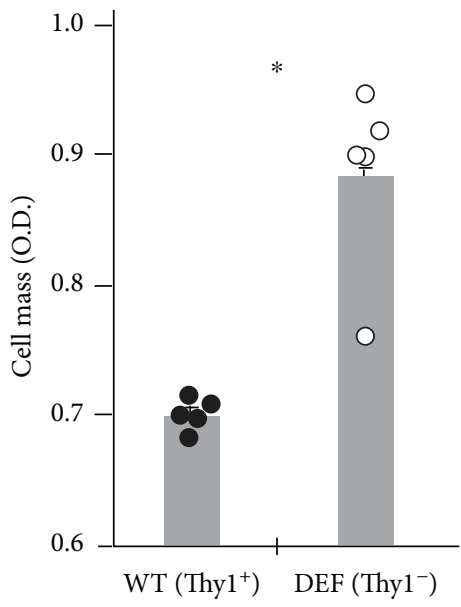

(a)
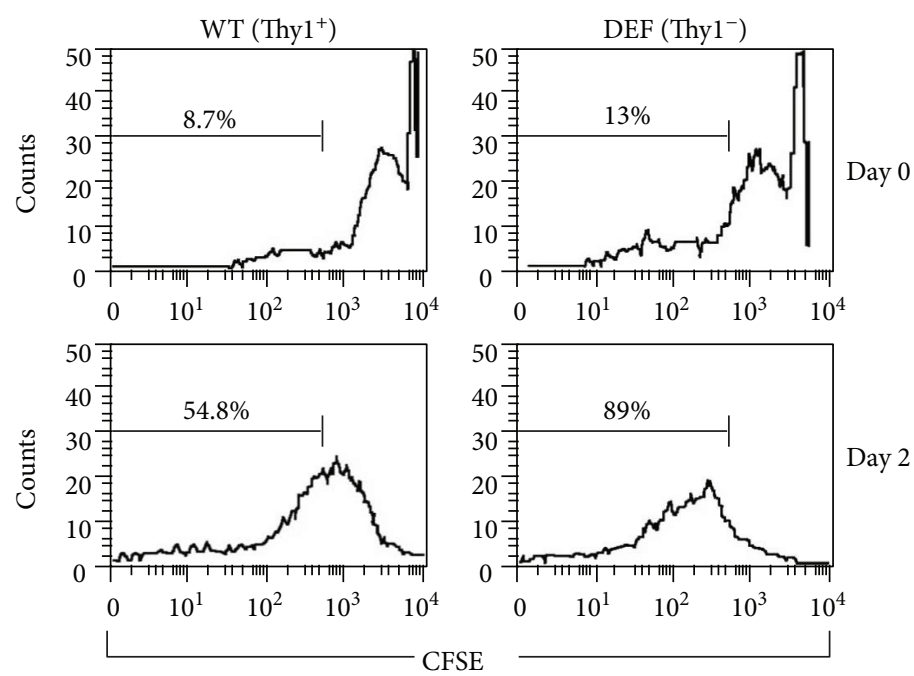

(b)
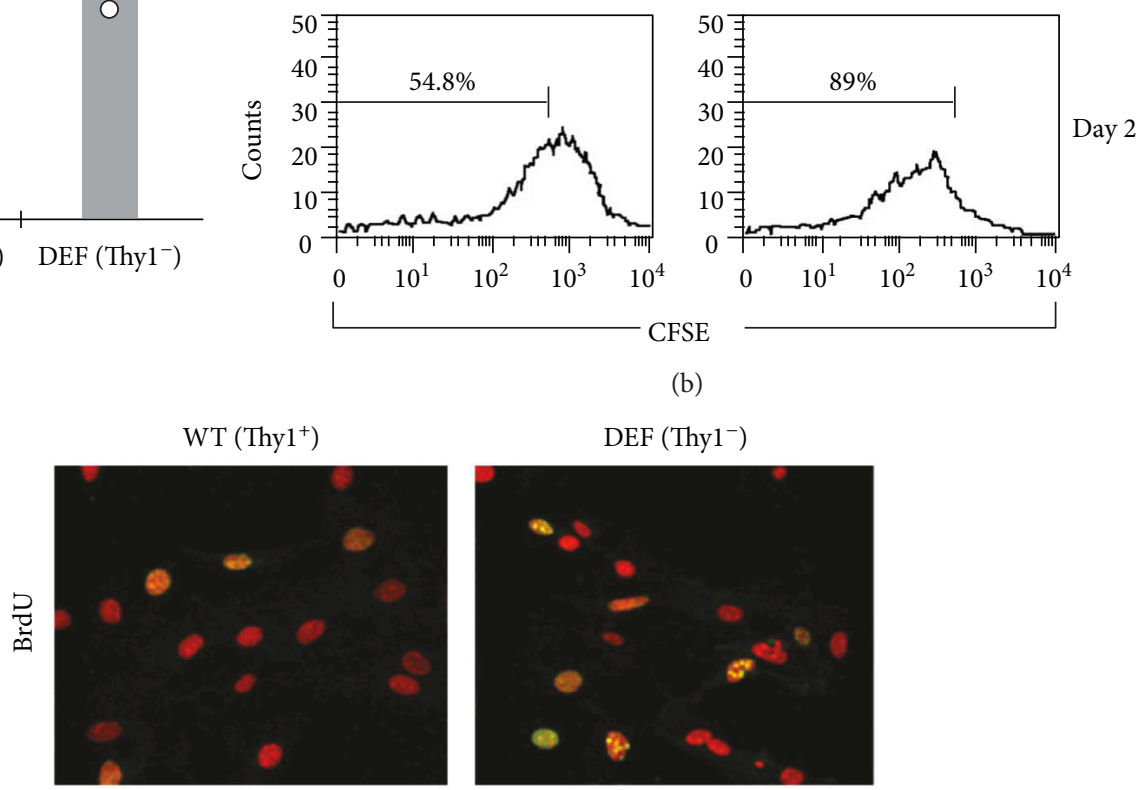

(c)

Figure 5: Proliferation rates of Thy $1^{+}$and Thy $1^{-}$myofibroblasts isolated from the fibrotic lungs. Lung cells were removed from bleomycintreated mice at 14-day post-IT. Primary lung myofibroblast cultures were obtained and maintained in RPMI medium. The cultures were sorted by FACS using PE-conjugated anti-Thy1 (CD90) mAb to isolate Thy1 ${ }^{-}$and Thyl $^{+}$myofibroblasts. (a) Cell mass of Thy ${ }^{+}$and Thy $1^{-}$myofibroblasts measured after $24 \mathrm{~h}$, by methylene blue staining followed by colorimetric assay. Results are presented as fold change from day $0\left({ }^{*} p<0.05\right)$. (b) CFSE staining primary cultures of Thy $1^{+}$and Thy $1^{-}$myofibroblasts were stained with CFSE. After $72 \mathrm{~h}$ of incubation, intensity of CFSE labeling was measured by flow cytometry. The percentage of the cells that lost CFSE labeling at days 0 and 3 is noted. (c) BrdU uptake Thy1 ${ }^{+}$and Thy1 ${ }^{-}$myofibroblasts were treated with $20 \mu \mathrm{M}$ BrdU for 6 h. BrdU uptake was assessed by antiBrdU-FITC-conjugated $\mathrm{mAb}$ staining and subjected to confocal microscopy analysis. 

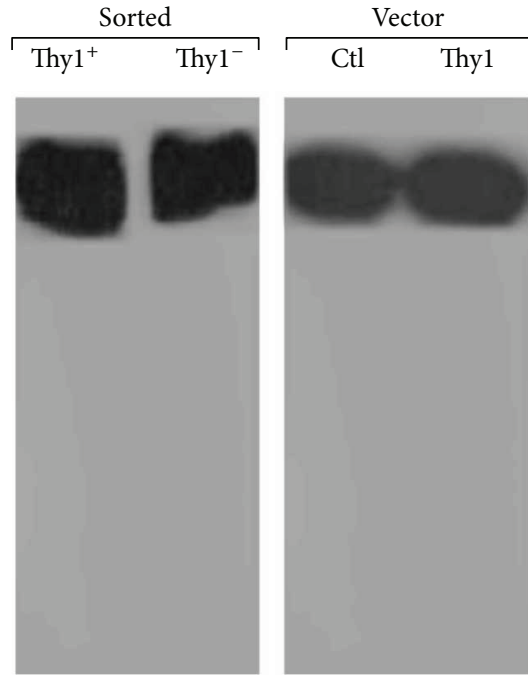

(a)
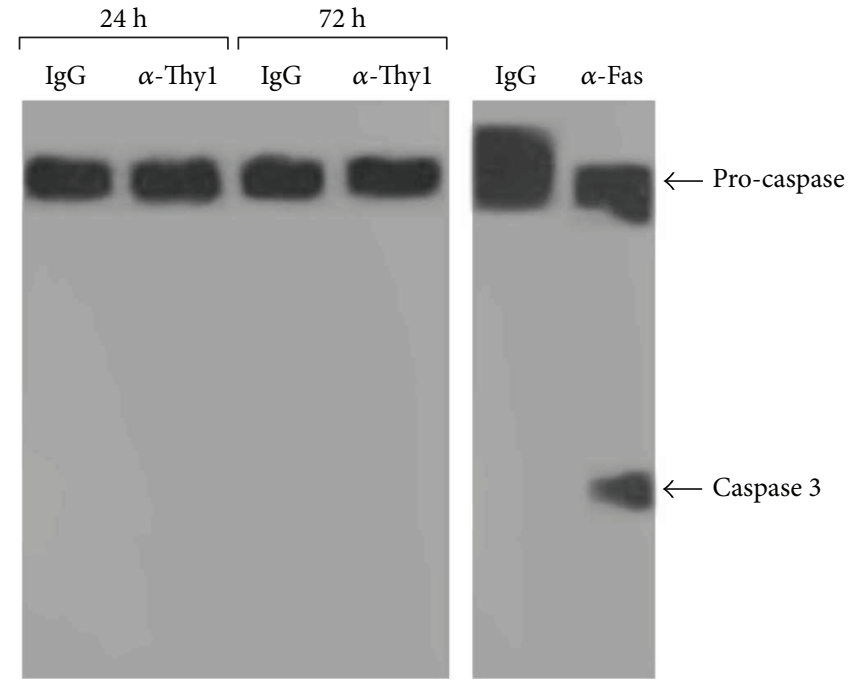

(b)

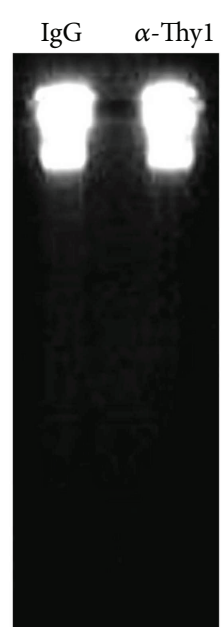

(c)

FIgURE 6: Thy1 expression is not involved in the regulation of fibroblast apoptosis. (a) Western blots determining the extent of pro-caspase 3 cleavage (apoptosis) in Thy $1^{+}$or Thy $1^{-}$sorted fibroblasts from the lungs of bleomycin-treated mice and in a lung fibroblast cell line (Mlg) transfected with a Thy1.2 expression vector or plasmid-containing Thyl cDNA in antisense orientation and in murine primary lung myofibroblasts transfected with Thyl siRNA or control siRNA. (b) Western blot of pro-caspase 3 cleavage. (c) DNA ladder in lung fibroblast primary cultures following stimulation with G7 anti-Thy1 mAb (5 $\mathrm{g} / \mathrm{ml})$ or IgG isotype match control for 24-72 h.

shown that Thy $1^{-}$myofibroblasts have higher $\alpha$-SMA expression compared to their Thy $1^{+}$counterparts [58]. As previously shown by others [59], and as we hypothesized and show here (Figure 7), during differentiation of fibroblasts to myofibroblasts (new synthesis of $\alpha$-SMA), Thyl expression is decreased, rendering activated Thy ${ }^{-}$myofibroblasts. To this end, murine primary lung myofibroblasts were stimulated with TGF $\beta$ for $72 \mathrm{~h}$ and stained for Thy 1 and $\alpha$-SMA. While myofibroblast $\alpha$-SMA expression was increased following TGF $\beta$ stimulation, as determined by visual increase in cell staining in confocal microscope (Figure $7(\mathrm{a})$ ) and by quantification of mean fluorescence intensity (MFI) by flow cytometry (Figures 7(b) and 7(c)), Thyl expression was decreased (Figure 7), indicating that differentiation of fibroblasts into myofibroblasts is associated with downregulation of Thyl protein expression. This may serve as another mechanism increasing the Thy $1^{-}$myofibroblast population during lung fibrosis.

In addition, as we have shown in our previous publication [15], gene chip analysis revealed that Thyl activation as detailed by Cohen et al. [46] downregulates expression of some genes that have a role in myofibroblast differentiation and actin cytoskeleton regulation. Three genes are of special interest here. Two of them, Pax7 [60] and MyoD [61], are master muscle differentiation regulatory genes; the third is $\alpha$-SMA, which is known as a myofibroblast cell marker. The inhibitory effects of Thyl activation on myofibroblast differentiation and gene expression explain the necessity of Thy1 downregulation to allow myofibroblast differentiation. 

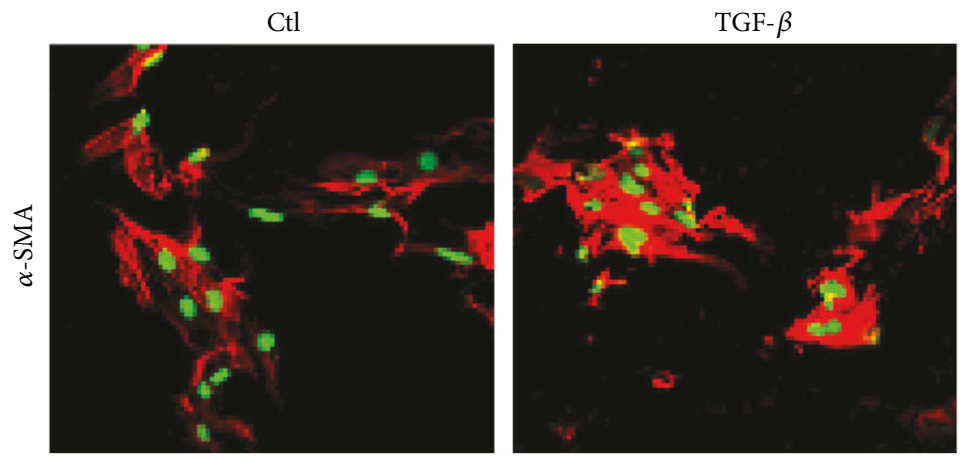

(a)

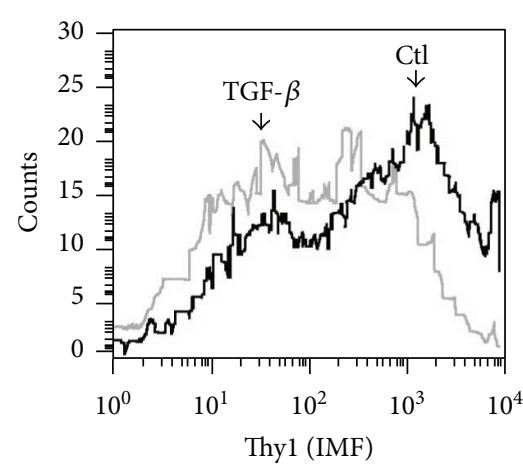

(b)

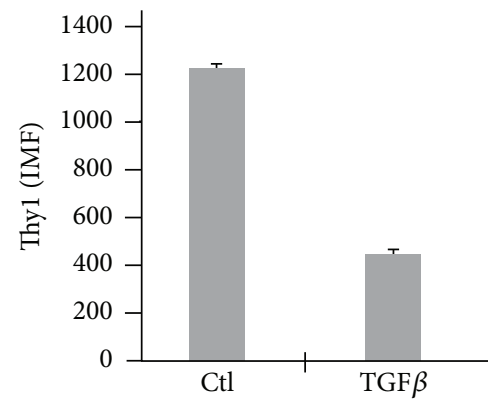

(c)

Figure 7: Decrease in Thy1 fibroblast expression during myofibroblast differentiation. Lung myofibroblasts in primary culture were stimulated for $72 \mathrm{~h}$ with TGF $\beta(2 \mathrm{ng} / \mathrm{ml})$. (a) Cells were fixed and stained with anti- $\alpha$-SMA antibody (red) and PI (green) and analyzed by confocal microscope. (b) Cells were stained using PE-conjugated anti-Thyl and analyzed by FACS. (c) Graphical presentation of results from (b).

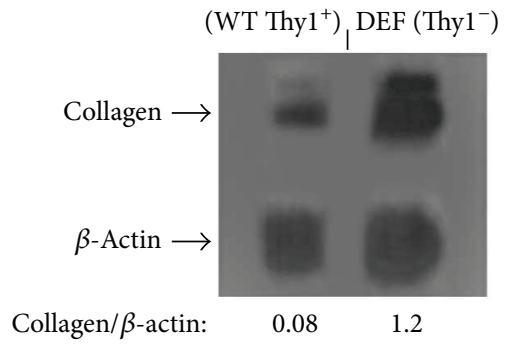

(a)

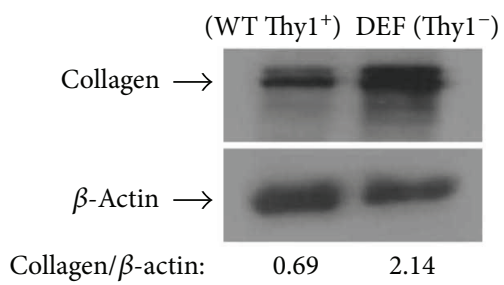

(b)

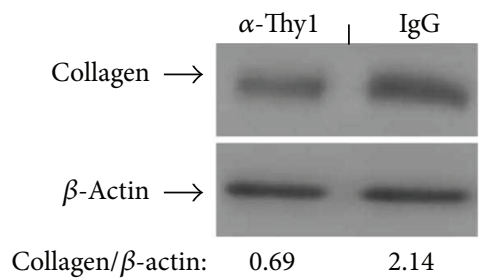

(c)

FIgURE 8: Thy1 expression is involved in the regulation of collagen in fibroblasts. QPCR (a) and Western blots (b-c) determining the extent of collagen expression in $\mathrm{Thyl}^{+}$(a) or Thyl ${ }^{-}$(b) sorted fibroblasts from the lungs of bleomycin-treated mice and in (c) naïve lung fibroblast primary cultures following stimulation with G7 anti-Thyl $\mathrm{mAb}(5 \mu \mathrm{g} / \mathrm{ml})$ or IgG isotype match control for 24-72 $\mathrm{h}$.

\subsection{Thy $1^{-}$Myofibroblasts from the Fibrotic Lungs Increase} Collagen Protein and RNA Levels Than Thy $1^{+}$ Myofibroblasts. To extend the in vitro findings performed in naïve cells (Figures 1-4) to the in vivo model of lung fibrosis, we compared the collagen protein and gene expression of $\mathrm{Thyl}^{+}$and $\mathrm{Thyl}^{-}$myofibroblasts isolated from the fibrotic lungs and collagen protein expression in myofibroblasts that were stimulated with G7 anti-Thy1 $\mathrm{mAb}(10 \mu \mathrm{g} / \mathrm{ml})$. As shown in Figure 8 , collagen protein expression is downregulated at the RNA level (Figure 8(a)) and protein level (Figure $8(\mathrm{~b})$ ) in $\mathrm{Thyl}^{+}$compared to
Thy $1^{-}$fibrotic lung myofibroblasts. Moreover, direct activation of Thyl receptor by specific anti-Thyl mAb ( $\alpha$-Thy1) versus control ( $\mathrm{IgG}$ ) decreased the extent of spontaneous collagen production in naïve lung myofibroblasts (Figure $8(\mathrm{c})$ ).

Abnormal myofibroblast accumulation and collagen deposition are characteristics of lung fibrosis [62, 63]. Myofibroblasts are thought to be primarily responsible for increased deposition of collagen within the lung $[55,64]$. We have previously shown that Thyl activation downregulates genes promoting fibroblast cell survival and differentiation [15], functions that are considered to be profibrotic. In 
this case, Thy 1 may also serve as a protector against fibroblast overactivity, as shown by others who report an inverse correlation between Thyl expression on fibroblasts and the evolution of lung fibrosis $[16,65]$.

The increased number of myofibroblasts accumulating in lung fibrosis may be due to their increased proliferation, their resistance to apoptosis, or both. We have found that Thy $1^{-}$ myofibroblasts isolated from bleomycin-treated mice are more proliferative than $\mathrm{Thyl}^{+}$subsets (Figures $2-5$ ). Moreover, Thyl downregulation increased myofibroblast proliferation, and exogenic upregulation of Thyl decreased it (Figure 3), indicating that Thy1 has an inhibitory effect on myofibroblast proliferation.

These observations are consistent with previous reports showing in vitro that Thy $1^{-}$fibroblasts are more proliferative than those which are Thy $1^{+}$when exposed to fibrogenic cytokines and growth factors [28], both in lung sections of bleomycin-treated mice and in humans with IPF [16]. Nevertheless, in naïve mice, no significant difference in cell growth rates between Thy $1^{+}$and Thy $1^{-}$fibroblasts was detected [11], possibly due to differences in the in vivo milieu of these naïve and the bleomycin-treated mice above.

The inhibitory effect of Thyl on cell proliferation was also demonstrated in neurite outgrowth [66] and tumor growth $[25,26,29]$. Inhibition of cell proliferation is related to a GPI-linked protein, as demonstrated in T cells [34], and there is precedent for a role of Src kinase in $\mathrm{T}$ cell growth inhibition [67]. Consistent with these observations, we have shown that Thyl activation in myofibroblasts induces Src phosphorylation [46], which may have inhibitory effect on myofibroblast growth.

Alternatively, Thy 1 may attenuate lung myofibroblast proliferation indirectly by downregulating receptors such as Fgf and Angtl, which control fibroblast proliferation $[52,53]$, as we have shown by gene chip analysis [15] and validated by real-time PCR (Figure 4). The decrease in these receptors' expression may reduce transmission of proproliferation signals to fibroblasts and thereby attenuate myofibroblast proliferation.

We found no difference between WT and chimeric Thy1deficient mice with WT lymphocytes and Thyl-deficient mesenchymal cells, when compared to control the salinetreated mouse lungs in assessments of lung fibrotic injury by semiquantitative morphological index of pathological sections, as well as collagen content [15]. In Thyl null mice, Thy1 is absent from all cells that would otherwise express it, in contrast to our chimeric Thy1-deficient mice, whose lymphocytes express Thy1. Because Thy1 is normally expressed on murine lymphocytes, it is possible that the severe lung fibrosis following bleomycin IT that develops in Thyl null mice, is not due to changes in fibroblast Thyl expression, but rather is due to changes in lymphocyte function [68]. However, the role of lymphocytes in bleomycininduced lung fibrosis remains controversial, as does the role of inflammation in IPF [4, 69-74].

Gene chip analysis revealed that Thy 1 activation downregulated expression of several other genes that have a role in lung fibroblast proliferation, including cell cycle, MAPK [47], and insulin signaling pathway genes [15, 49, 75]. Taken together with our earlier findings [15], these results provide a possible explanation for the mechanism for Thyl expression attenuation of lung myofibroblast proliferation.

Neither activation nor exogenic upregulation or downregulation of Thyl expression led to any change in fibroblast apoptosis (Figure 6); however, it may be possible that Thy1 can indirectly influence myofibroblast susceptibility to apoptosis that is triggered by other factors. It has been shown that angiotensin II and TGF- $\beta$ protect fibroblasts from apoptosis $[76,77]$. Indeed, we show that Thy 1 activation downregulates angiotensin II and pathway genes affecting TGF- $\beta$ signaling [15] and therefore may increase myofibroblast capacity to undergo apoptosis. This is consistent with a previous report showing that Thy $1^{+}$fibroblasts were more sensitive to apoptosis induction [58]. Myofibroblasts are the major cellular component in IPF fibroblastic foci [54]. Gene chip analysis revealed that Thy 1 activation downregulates $\alpha$ SMA expression [15]. This is consistent with a previous report showing that Thy $1^{-}$myofibroblasts have higher $\alpha$ SMA expression compared to Thy $1^{+}$[58]. Moreover, Thy1 activation downregulated the expression of genes known to have a role in myofibroblast differentiation, such as Pax7 [60] and MyoD [61], which are master regulatory genes of muscle differentiation. This is consistent with a previous report showing enhancement of myofibroblast differentiation marker in Thy $1^{-}$compared to Thy $1^{+}$fibroblasts [58]. Moreover, the inhibitory effect of Thyl activation on the expression of genes involved in myofibroblast differentiation explains the necessity of Thy1 downregulation for myofibroblast differentiation. Indeed, we show that induction of myofibroblast differentiation (e.g., $\alpha$-SMA expression) by TGF- $\beta$ stimulation was associated with reduction of Thyl expression (Figure 7(a)). In addition, in bleomycin-treated mice, the number of $\alpha$-SMA-positive cells increased $[78,79]$ when myofibroblast expression of Thy1 decreased (Figure 7(b)).

In addition, TGF- $\beta$ is a key mediator of lung fibrosis [80, 81]. It stimulates fibroblast proliferation and migration [51], induces ECM production [82, 83], and promotes myofibroblast differentiation [84]. We show here that Thy1-deficient cells overexpress collagen at the RNA (Figure $8(\mathrm{a})$ ) and protein (Figure 8(b)) levels. Moreover, Thyl stimulation decreased collagen protein levels in naïve lung fibroblasts (Figure 8(c)). Our gene chip analysis revealed that Thy1 activation downregulates downstream molecules of the TGF- $\beta$ signaling pathway [15]. This finding is consistent with other observations showing that Thyl limits the ability of fibroblasts to activate TGF- $\beta$ [41], and Thy1 null mice have higher TGF- $\beta$ compared to WT mice following bleomycin instillation [16]. Since TGF- $\beta$ stimulates fibroblast proliferation [51], deceased expression of genes involved in TGF- $\beta$ signaling may reduce the transmission of proproliferation signals to fibroblasts, leading to the attenuation of their proliferation.

\section{Conclusions}

These findings indicate that decreases of Thy $1^{+}$lung myofibroblast subsets in lung fibrosis increase their proliferative functions. Thyl is critical and not only associated with the downregulation/control of genes promoting cell survival 
and proliferation, fibroblast differentiation, and collagen production as thoroughly assessed by genetic manipulations in $\mathrm{Thy}^{+}$and in mirror experiments with Thy ${ }^{-}$lung fibroblasts.

\section{Abbreviations}

AGRT: Angiotensin receptor

BAL: Bronchoalveolar lavage

BrdU: Bromodeoxyuridine staining

cDNA: Complementary DNA

CFSE: Carboxyfluorescein diacetate succinimidyl ester

Ct: Target gene

ECM: $\quad$ Extracellular matrix

FCS: $\quad$ Fluorescence-activated cell sorting

FGFR: Fibroblast growth factor receptor

FITC: Fluorescein isothiocyanate

GPI: Glycosylphosphatidylinositol

h: Hour

IP: Intraperitoneal injection

IPF: Idiopathic pulmonary fibrosis

IT: Intratracheal injection

mAb: Monoclonal antibody b

min: $\quad$ Minutes

PBS: $\quad$ Phosphate-buffered saline

PE: $\quad$ Phycoerythrin

qPCR: Quantitative polymerase chain reaction

RPM: Revolutions per minute

RT: $\quad$ Room temperature

RT-PCR: Reverse transcription polymerase chain reaction

sec: $\quad$ Seconds

siRNA: Small-interfering RNA

TGF: Transforming growth factor

Thy ${ }^{-}$: $\quad$ Thy1-negative

Thy ${ }^{+}$: $\quad$ Thyl-positive

WT: Wild-type

$\alpha$-SMA: $\alpha$-Smooth muscle actin.

\section{Conflicts of Interest}

The authors have no competing interests to disclose.

\section{Authors' Contributions}

Pazit Y. Cohen contributed to research design and performed all experimental work and primary data analysis, prepared the initial draft of the paper, and contributed to revisions. Raphael Breuer contributed to research concept and strategy, supervised the project, and critically revised the paper. Shulamit B. Wallach-Dayan conceived the research concept and strategies, supervised the study and data analysis, and critically revised the paper. All authors reviewed the final version of the paper and accept responsibility for the accuracy and integrity of the research findings reported here.

\section{Acknowledgments}

This work was supported by the Israel Science Foundation and the Gutenberg Fund. The authors thank Shifra Fraifeld for her editorial assistance in preparing this paper.

\section{References}

[1] M. I. Schwarz and T. E. King, "Principles of approach to the patient with interstitial lung disease," in Textbook of Respiratory Medicine, J. F. Murray and J. A. Nadel, Eds., W.B. Saunders Company, Philadelphia, PA, USA, 3rd edition, 2000.

[2] S. B. Sulavik, "A clinician's view," in Pulmonary Fibrosis: Lung Biology in Health and Disease, S. H. Phan and R. S. Thrall, Eds., Marcel Dekker, Inc., New York, 1995.

[3] S. B. Wallach-Dayan, L. Elkayam, R. Golan-Gerstl et al., "Cutting edge: $\mathrm{FasL}^{+}$immune cells promote resolution of fibrosis," Journal of Autoimmunity, vol. 59, pp. 67-76, 2015.

[4] S. W. Glasser, J. S. Hagood, S. Wong, C. A. Taype, S. K. Madala, and W. D. Hardie, "Mechanisms of lung fibrosis resolution," The American Journal of Pathology, vol. 186, no. 5, pp. 1066-1077, 2016.

[5] H. P. Rodemann and G. A. Müller, "Abnormal growth and clonal proliferation of fibroblasts derived from kidneys with interstitial fibrosis," Experimental Biology and Medicine, vol. 195, no. 1, pp. 57-63, 1990.

[6] G. Raghu, Y. Chen, V. Rusch, and P. S. Rabinovitch, "Differential proliferation of fibroblasts cultured from normal and fibrotic human lungs," American Review of Respiratory Disease, vol. 138, no. 3, pp. 703-708, 1988.

[7] Y. P. Moodley, P. Caterina, A. K. Scaffidi et al., "Comparison of the morphological and biochemical changes in normal human lung fibroblasts and fibroblasts derived from lungs of patients with idiopathic pulmonary fibrosis during FasL-induced apoptosis," The Journal of Pathology, vol. 202, no. 4, pp. 486-495, 2004.

[8] T. Tanaka, M. Yoshimi, T. Maeyama, N. Hagimoto, K. Kuwano, and N. Hara, "Resistance to Fas-mediated apoptosis in human lung fibroblast," European Respiratory Journal, vol. 20, no. 2, pp. 359-368, 2002.

[9] S. B. Wallach-Dayan, R. Golan-Gerstl, and R. Breuer, "Evasion of myofibroblasts from immune surveillance: a mechanism for tissue fibrosis," Proceedings of the National Academy of Sciences of the United States of America, vol. 104, no. 51, pp. 20460-20465, 2007.

[10] K. M. Fries, T. Blieden, R. J. Looney et al., "Evidence of fibroblast heterogeneity and the role of fibroblast subpopulations in fibrosis," Clinical Immunology and Immunopathology, vol. 72, no. 3, pp. 283-292, 1994.

[11] D. P. Penney, P. C. Keng, S. Derdak, and R. P. Phipps, "Morphologic and functional characteristics of subpopulations of murine lung fibroblasts grown in vitro," The Anatomical Record, vol. 232, no. 3, pp. 432-443, 1992.

[12] F. Plata, F. Garcia-Pons, A. Ryter et al., "HIV-1 infection of lung alveolar fibroblasts and macrophages in humans," AIDS Research and Human Retroviruses, vol. 6, no. 8, pp. 979-986, 1990.

[13] V. F. Fiore, P. W. Strane, A. V. Bryksin, E. S. White, J. S. Hagood, and T. H. Barker, "Conformational coupling of integrin and Thy-1 regulates Fyn priming and fibroblast mechanotransduction," The Journal of Cell Biology, vol. 211, no. 1, pp. 173-190, 2015.

[14] X. Liu, S. S. Wong, C. A. Taype et al., "Thy-1 interaction with Fas in lipid rafts regulates fibroblast apoptosis and lung injury resolution," Laboratory Investigation, vol. 97, no. 3, pp. 256267, 2017.

[15] P. Y. Cohen, R. Breuer, P. Zisman, and S. B. WallachDayan, "Bleomycin-treated chimeric Thyl-deficient mice 
with Thy1-deficient myofibroblasts and Thy-positive lymphocytes resolve inflammation without affecting the fibrotic response," Mediators of Inflammation, vol. 2015, Article ID 942179, 13 pages, 2015.

[16] J. S. Hagood, P. Prabhakaran, P. Kumbla et al., "Loss of fibroblast Thy-1 expression correlates with lung fibrogenesis," The American Journal of Pathology, vol. 167, no. 2, pp. 365-379, 2005.

[17] A. F. Williams and A. G. -D. Tse, "A glycophospholipid covalently attached to the C-terminus of the Thy-1 glycoprotein," Bioscience Reports, vol. 5, no. 10-11, pp. 999-1005, 1985.

[18] T. A. Rege and J. S. Hagood, "Thy-1, a versatile modulator of signaling affecting cellular adhesion, proliferation, survival, and cytokine/growth factor responses," Biochimica et Biophysica Acta (BBA) - Molecular Cell Research, vol. 1763, no. 10, pp. 991-999, 2006.

[19] N. Fujita, Y. Kato, M. Naito, and T. Tsuruo, "A novel anti-Thy1 (CD90) monoclonal antibody induces apoptosis in mouse malignant T-lymphoma cells in spite of inducing bcl-2 expression," International Journal of Cancer, vol. 66, no. 4, pp. 544550, 1996.

[20] N. Fujita, N. Kodama, Y. Kato, S. H. Lee, and T. Tsuruo, "Aggregation of Thy-1 glycoprotein induces thymocyte apoptosis through activation of CPP32-like proteases," Experimental Cell Research, vol. 232, no. 2, pp. 400-406, 1997.

[21] A. O. Hueber, G. Raposo, M. Pierres, and H. T. He, "Thy-1 triggers mouse thymocyte apoptosis through a bcl-2-resistant mechanism," Journal of Experimental Medicine, vol. 179, no. 3, pp. 785-796, 1994.

[22] H. Morita, K. Isobe, Z. Cai et al., "Thy-1 antigen mediates apoptosis of rat glomerular cells in vitro and in vivo," Nephron, vol. 73, no. 2, pp. 293-298, 1996.

[23] T. Sato, M. G. A. van Dixhoorn, W. E. M. Schroeijers et al., "Apoptosis of cultured rat glomerular mesangial cells induced by IgG2a monoclonal anti-Thy-1 antibodies," Kidney International, vol. 49, no. 2, pp. 403-412, 1996.

[24] T. Sato, M. G. A. van Dixhoorn, W. E. M. Schroeijers, L. A. van Es, and M. R. Daha, "Efficient induction of apoptosis in cultured rat glomerular mesangial cells by dimeric monoclonal IgA anti-Thy-1 antibodies," Kidney International, vol. 51, no. 1, pp. 173-181, 1997.

[25] H. R. Abeysinghe, Q. Cao, J. Xu et al., "THY1 expression is associated with tumor suppression of human ovarian cancer," Cancer Genetics and Cytogenetics, vol. 143, no. 2, pp. 125-132, 2003.

[26] H. R. Abeysinghe, S. J. Pollock, N. L. Guckert et al., "The role of the THY1 gene in human ovarian cancer suppression based on transfection studies," Cancer Genetics and Cytogenetics, vol. 149, no. 1, pp. 1-10, 2004.

[27] S. M. M. Haeryfar and D. W. Hoskin, "Selective pharmacological inhibitors reveal differences between Thy-1- and T cell receptor-mediated signal transduction in mouse T lymphocytes," International Immunopharmacology, vol. 1, no. 4, pp. 689-698, 2001.

[28] J. S. Hagood, A. Mangalwadi, B. Guo, M. W. MacEwen, L. Salazar, and G. M. Fuller, "Concordant and discordant interleukin-1-mediated signaling in lung fibroblast Thy-1 subpopulations," American Journal of Respiratory Cell and Molecular Biology, vol. 26, no. 6, pp. 702-708, 2002.

[29] H. L. Lung, D. K. Bangarusamy, D. Xie et al., "THY1 is a candidate tumour suppressor gene with decreased expression in metastatic nasopharyngeal carcinoma," Oncogene, vol. 24, no. 43, pp. 6525-6532, 2005.

[30] Y. Sugimoto, Y. Ikawa, and H. Nakauchi, "Thy-1 as a negative growth regulator in ras-transformed mouse fibroblasts," Cancer Research, vol. 51, no. 1, pp. 99-104, 1991.

[31] H. Takeda, M. Yamamoto, N. Morita, and T. Tanizawa, "Relationship between Thy-1 expression and cell-cycle distribution in human bone marrow hematopoietic progenitors," American Journal of Hematology, vol. 79, no. 3, pp. 187-193, 2005.

[32] T. A. Rege and J. S. Hagood, "Thy-1 as a regulator of cell-cell and cell-matrix interactions in axon regeneration, apoptosis, adhesion, migration, cancer, and fibrosis," The FASEB Journal, vol. 20, no. 8, pp. 1045-1054, 2006.

[33] S. M. M. Haeryfar and D. W. Hoskin, "Thy-1: more than a mouse pan-T cell marker," The Journal of Immunology, vol. 173, no. 6, pp. 3581-3588, 2004.

[34] M. D. Marmor, M. F. Bachmann, P. S. Ohashi, T. R. Malek, and M. Julius, "Immobilization of glycosylphosphatidylinositolanchored proteins inhibits T cell growth but not function," International Immunology, vol. 11, no. 9, pp. 1381-1393, 1999.

[35] M. D. Marmor and M. Julius, "The function of GPI-anchored proteins in $\mathrm{T}$ cell development, activation and regulation of homeostasis," Journal of Biological Regulators and Homeostatic Agents, vol. 14, no. 2, pp. 99-115, 2000.

[36] J. S. Hagood, P. J. Miller, J. A. Lasky et al., "Differential expression of platelet-derived growth factor- $\alpha$ receptor by Thy-1 ${ }^{-}$ and Thy $-1^{+}$lung fibroblasts," American Journal of Physiology-Lung Cellular and Molecular Physiology, vol. 277, no. 1, pp. L218-L224, 1999.

[37] R. P. Phipps, C. Baecher, J. G. Frelinger, D. P. Penney, P. Keng, and D. Brown, "Differential expression of interleukin $1 \alpha$ by Thy $-1^{+}$and Thy-1 $1^{-}$lung fibroblast subpopulations: enhancement of interleukin $1 \alpha$ production by tumor necrosis factor- $\alpha$," European Journal of Immunology, vol. 20, no. 8, pp. 1723-1727, 1990.

[38] M. R. Silvera and R. P. Phipps, "Synthesis of interleukin-1 receptor antagonist by Thy $-1^{+}$and Thy- $1^{-}$murine lung fibroblast subsets," Journal of Interferon \& Cytokine Research, vol. 15, no. 1, pp. 63-70, 1995.

[39] M. R. Silvera, G. D. Sempowski, and R. P. Phipps, "Expression of TGF-beta isoforms by Thy-1+ and Thy-1pulmonary fibroblast subsets: evidence for TGF-beta as a regulator of IL-1-dependent stimulation of IL-6," Lymphokine and Cytokine Research, vol. 13, no. 5, pp. 277-285, 1994.

[40] J. S. Hagood, J. A. Lasky, J. E. Nesbitt, and P. Segarini, “Differential expression, surface binding, and response to connective tissue growth factor in lung fibroblast subpopulations," Chest, vol. 120, no. 1, Supplement, pp. S64-S66, 2001.

[41] Y. Zhou, J. S. Hagood, and J. E. Murphy-Ullrich, "Thy-1 expression regulates the ability of rat lung fibroblasts to activate transforming growth factor- $\beta$ in response to fibrogenic stimuli," The American Journal of Pathology, vol. 165, no. 2, pp. 659-669, 2004.

[42] T. H. Barker, H. E. Grenett, M. W. MacEwen et al., "Thy-1 regulates fibroblast focal adhesions, cytoskeletal organization and migration through modulation of p190 RhoGAP and Rho GTPase activity," Experimental Cell Research, vol. 295, no. 2, pp. 488-496, 2004.

[43] M. H. Oliver, N. K. Harrison, J. E. Bishop, P. J. Cole, and G. J. Laurent, "A rapid and convenient assay for counting cells 
cultured in microwell plates: application for assessment of growth factors," Journal of Cell Science, vol. 92, Part 3, pp. 513-518, 1989.

[44] A. B. Lyons, "Analysing cell division in vivo and in vitro using flow cytometric measurement of CFSE dye dilution," Journal of Immunological Methods, vol. 243, no. 1-2, pp. 147-154, 2000.

[45] H. Kojima, M. Toda, and M. V. Sitkovsky, "Comparison of Fas-versus perforin-mediated pathways of cytotoxicity in TCR- and Thy-1-activated murine T cells," International Immunology, vol. 12, no. 3, pp. 365-374, 2000.

[46] P. Y. Cohen, R. Breuer, and S. B. Wallach-Dayan, "Thy1 upregulates FasL expression in lung myofibroblasts via Src family kinases," American Journal of Respiratory Cell and Molecular Biology, vol. 40, no. 2, pp. 231-238, 2009.

[47] T. Makino, M. Jinnin, F. C. Muchemwa et al., "Basic fibroblast growth factor stimulates the proliferation of human dermal fibroblasts via the ERK1/2 and JNK pathways," British Journal of Dermatology, vol. 162, no. 4, pp. 717-723, 2010.

[48] M. Molina-Molina, J. Pereda, and A. Xaubet, "Experimental models for the study of pulmonary fibrosis: current usefulness and future promise," Archivos de Bronconeumología ((English Edition)), vol. 43, no. 9, pp. 501-507, 2007.

[49] J. Y. Qi, M. Xu, Z. Z. Lu, and Y. Y. Zhang, "14-3-3 inhibits insulin-like growth factor-I-induced proliferation of cardiac fibroblasts via a phosphatidylinositol 3-kinase-dependent pathway," Clinical and Experimental Pharmacology and Physiology, vol. 37, no. 3, pp. 296-302, 2010.

[50] H. Chen, W.-W. Yang, Q.-T. Wen, L. Xu, and M. Chen, “TGF$\beta$-induced fibroblast activation protein expression, fibroblast activation protein expression increases the proliferation, adhesion, and migration of HO-8910PM," Experimental and Molecular Pathology, vol. 87, no. 3, pp. 189-194, 2009.

[51] T. Schreier, E. Degen, and W. Baschong, "Fibroblast migration and proliferation during in vitro wound healing," Research in Experimental Medicine, vol. 193, no. 1, pp. 195-205, 1993.

[52] F. Strutz, M. Zeisberg, B. Hemmerlein et al., "Basic fibroblast growth factor expression is increased in human renal fibrogenesis and may mediate autocrine fibroblast proliferation," Kidney International, vol. 57, no. 4, pp. 1521-1538, 2000.

[53] R. P. Marshall, R. J. McAnulty, and G. J. Laurent, “Angiotensin II is mitogenic for human lung fibroblasts via activation of the type 1 receptor," American Journal of Respiratory and Critical Care Medicine, vol. 161, no. 6, pp. 1999-2004, 2000.

[54] S. H. Phan, "Fibroblast phenotypes in pulmonary fibrosis," American Journal of Respiratory Cell and Molecular Biology, vol. 29, no. 3, Supplement, pp. S87-S92, 2003.

[55] K. Zhang, M. D. Rekhter, D. Gordon, and S. H. Phan, "Myofibroblasts and their role in lung collagen gene expression during pulmonary fibrosis. A combined immunohistochemical and in situ hybridization study," The American Journal of Pathology, vol. 145, no. 1, pp. 114-125, 1994.

[56] A. Desmouliere, A. Geinoz, F. Gabbiani, and G. Gabbiani, "Transforming growth factor-beta 1 induces alpha-smooth muscle actin expression in granulation tissue myofibroblasts and in quiescent and growing cultured fibroblasts," The Journal of Cell Biology, vol. 122, no. 1, pp. 103-111, 1993.

[57] D. L. Mattey, P. T. Dawes, N. B. Nixon, and H. Slater, "Transforming growth factor $\beta 1$ and interleukin 4 induced alpha smooth muscle actin expression and myofibroblast-like differentiation in human synovial fibroblasts in vitro: modulation by basic fibroblast growth factor," Annals of the Rheumatic Diseases, vol. 56, no. 7, pp. 426-431, 1997.

[58] Y. Y. Sanders, P. Kumbla, and J. S. Hagood, "Enhanced myofibroblastic differentiation and survival in Thy-1(-) lung fibroblasts," American Journal of Respiratory Cell and Molecular Biology, vol. 36, no. 2, pp. 226-235, 2007.

[59] J. Lu, Q. Liu, L. Wang et al., "Increased expression of latent TGF- $\beta$-binding protein 4 affects the fibrotic process in scleroderma by TGF- $\beta$ /SMAD signaling," Laboratory Investigation, vol. 97, no. 5, pp. 591-601, 2017.

[60] M. R. Ziman, M. Thomas, P. Jacobsen, and L. Beazley, "A key role for Pax7 transcripts in determination of muscle and nerve cells," Experimental Cell Research, vol. 268, no. 2, pp. 220-229, 2001.

[61] S. J. Tapscott, "The circuitry of a master switch: Myod and the regulation of skeletal muscle gene transcription," Development, vol. 132, no. 12, pp. 2685-2695, 2005.

[62] C. Khun, "Pathology in pulmonary fibrosis," in Pulmonary Fibrosis: Lung Biology in Health and Disease, S. H. Phan and R. S. Thrall, Eds., pp. 59-83, Marcel Dekker, New York, 1995.

[63] C. Kuhn, "Pathology in pulmonary fibrosis," in Pulmonary Fibrosis: Lung Biology in Health and Disease, S. H. Phan and R. S. Thrall, Eds., pp. 59-83, Marcel Dekker, New York, 1995.

[64] C. Kuhn and J. A. McDonald, "The roles of the myofibroblast in idiopathic pulmonary fibrosis. Ultrastructural and immunohistochemical features of sites of active extracellular matrix synthesis," The American Journal of Pathology, vol. 138, no. 5, pp. 1257-1265, 1991.

[65] J. C. McIntosh, J. S. Hagood, T. L. Richardson, and J. W. Simecka, "Thyl (+) and (-) lung fibrosis subpopulations in LEW and F344 rats," European Respiratory Journal, vol. 7, no. 12, pp. 2131-2138, 1994.

[66] M. C. Tiveron, E. Barboni, F. B. Pliego Rivero et al., "Selective inhibition of neurite outgrowth on mature astrocytes by Thy-1 glycoprotein," Nature, vol. 355, no. 6362, pp. 745748, 1992.

[67] E. F. Petricoin III, S. Ito, B. L. Williams et al., "Antiproliferative action of interferon- $\alpha$ requires components of T-cell-receptor signalling," Nature, vol. 390, no. 6660, pp. 629-632, 1997.

[68] S. Beissert, H. T. He, A. O. Hueber et al., "Impaired cutaneous immune responses in Thy-1-deficient mice," Journal of Immunology, vol. 161, no. 10, pp. 5296-5302, 1998.

[69] J. Gauldie, "Inflammatory mechanisms are a minor component of the pathogenesis of idiopathic pulmonary fibrosis," American Journal of Respiratory and Critical Care Medicine, vol. 165, no. 9, pp. 1205-1206, 2002.

[70] M. Helene, V. Lake-Bullock, J. Zhu, H. Hao, D. A. Cohen, and A. M. Kaplan, "T cell independence of bleomycin-induced pulmonary fibrosis," Journal of Leukocyte Biology, vol. 65, no. 2, pp. 187-195, 1999.

[71] B. B. Moore, J. A. McDonald, S. Sitterding, R. Paine, and G. B. Toews, "T cells protect against bleomycin-induced pulmonary fibrosis (abstract)," American Journal of Respiratory and Critical Care Medicine, vol. 159, p. A213, 1999.

[72] G. A. Rossi, S. Szapiel, V. J. Ferrans, and R. G. Crystal, "Susceptibility to experimental interstitial lung disease is modified by immune- and non-immune-related genes," American Review of Respiratory Disease, vol. 135, no. 2, pp. 448-455, 1987. 
[73] S. K. Sharma, J. A. MacLean, C. Pinto, and R. L. Kradin, "The effect of an anti-CD3 monoclonal antibody on bleomycininduced lymphokine production and lung injury," American Journal of Respiratory and Critical Care Medicine, vol. 154, no. 1, pp. 193-200, 1996.

[74] R. S. Thrall, J. R. McCormick, S. H. Phan, R. M. Jack, and P. A. Ward, "The effect of antilymphocyte globulin on the development of bleomycin-induced pulmonary fibrosis in the rat," American Review of Respiratory Disease, vol. 83, Supplement, p. 119, 1979.

[75] S. Monaco, M. Illario, M. R. Rusciano et al., "Insulin stimulates fibroblast proliferation through calcium-calmodulindependent kinase II," Cell Cycle, vol. 8, no. 13, pp. 20242030, 2009.

[76] L. Pattacini, B. Casali, L. Boiardi, N. Pipitone, L. Albertazzi, and C. Salvarani, "Angiotensin II protects fibroblast-like synoviocytes from apoptosis via the AT1-NF- $\kappa$ B pathway," Rheumatology, vol. 46, no. 8, pp. 1252-1257, 2007.

[77] H. Y. Zhang and S. H. Phan, "Inhibition of myofibroblast apoptosis by transforming growth factor $\beta_{1}$," American Journal of Respiratory Cell and Molecular Biology, vol. 21, no. 6, pp. 658-665, 1999.

[78] K. B. Adler, L. M. Callahan, and J. N. Evans, "Cellular alterations in the alveolar wall in bleomycin-induced pulmonary fibrosis in rats. An ultrastructural morphometric study," American Review of Respiratory Disease, vol. 133, no. 6, pp. 1043-1048, 1986.

[79] T. Osaki, K. Yoneda, Y. Tatemoto, T. Yamamoto, T. Yokoyama, and H. Enzan, "Peplomycin, a bleomycin derivative, induces myofibroblasts in pulmonary fibrosis," International Journal of Experimental Pathology, vol. 82, no. 4, pp. 231-241, 2001.

[80] S. N. Giri, D. M. Hyde, and M. A. Hollinger, "Effect of antibody to transforming growth factor beta on bleomycin induced accumulation of lung collagen in mice," Thorax, vol. 48, no. 10, pp. 959-966, 1993.

[81] P. J. Sime, Z. Xing, F. L. Graham, K. G. Csaky, and J. Gauldie, "Adenovector-mediated gene transfer of active transforming growth factor-betal induces prolonged severe fibrosis in rat lung," Journal of Clinical Investigation, vol. 100, no. 4, pp. 768-776, 1997.

[82] J. Keski-Oja, R. Raghow, M. Sawdey et al., "Regulation of mRNAs for type-1 plasminogen activator inhibitor, fibronectin, and type I procollagen by transforming growth factorbeta. Divergent responses in lung fibroblasts and carcinoma cells," Journal of Biological Chemistry, vol. 263, no. 7, pp. 3111-3115, 1988.

[83] R. P. Penttinen, S. Kobayashi, and P. Bornstein, “Transforming growth factor beta increases mRNA for matrix proteins both in the presence and in the absence of changes in mRNA stability," Proceedings of the National Academy of Sciences of the United States of America, vol. 85, no. 4, pp. 1105-1108, 1988.

[84] A. Desmouliere and G. Gabbiani, "Myofibroblast differentiation during fibrosis," Experimental Nephrology, vol. 3, no. 2, pp. 134-139, 1995. 


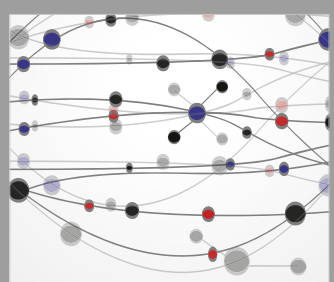

The Scientific World Journal
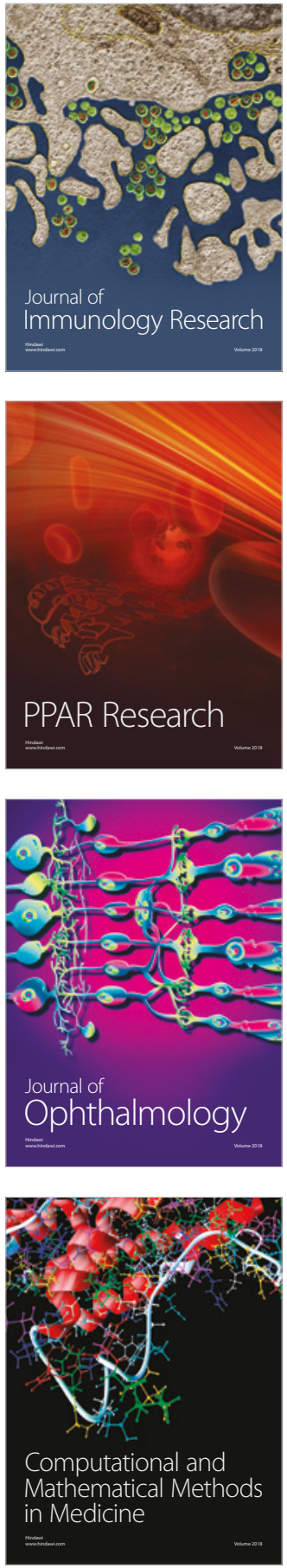

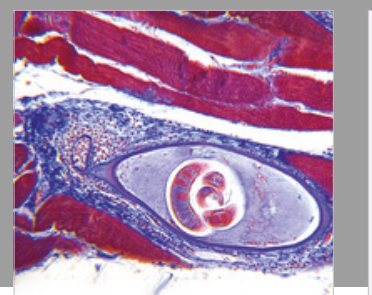

Gastroenterology Research and Practice

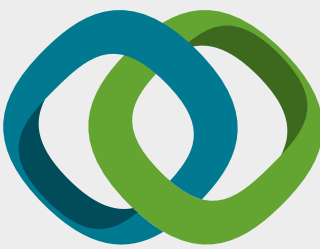

\section{Hindawi}

Submit your manuscripts at

www.hindawi.com
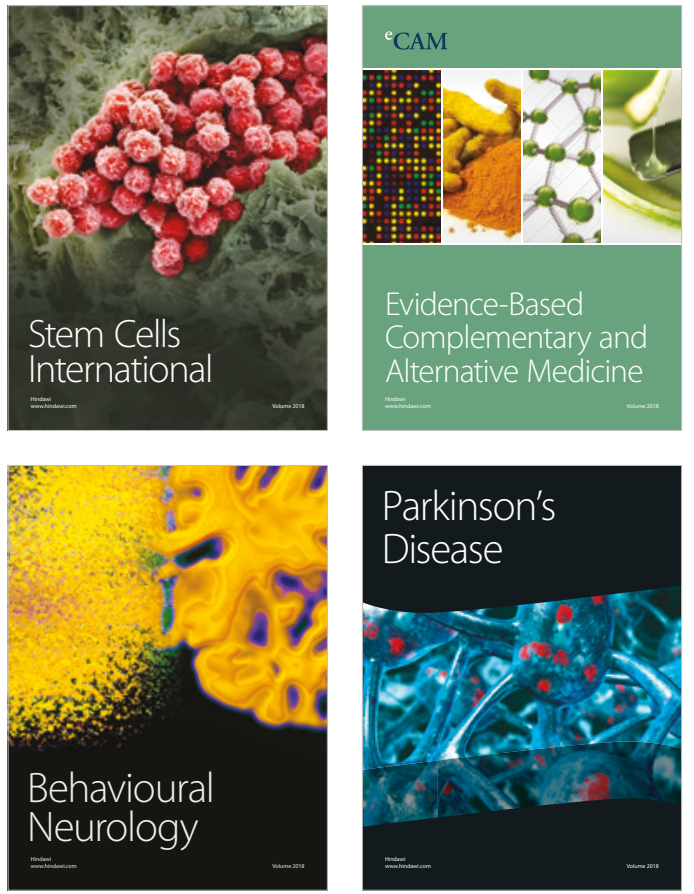

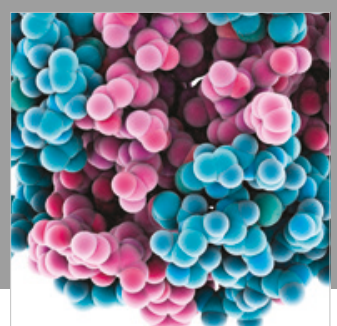

ournal of

Diabetes Research

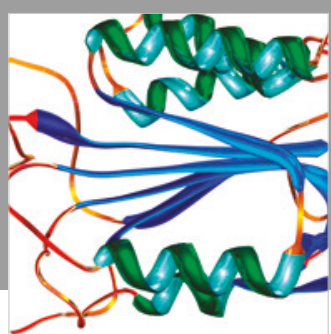

Disease Markers
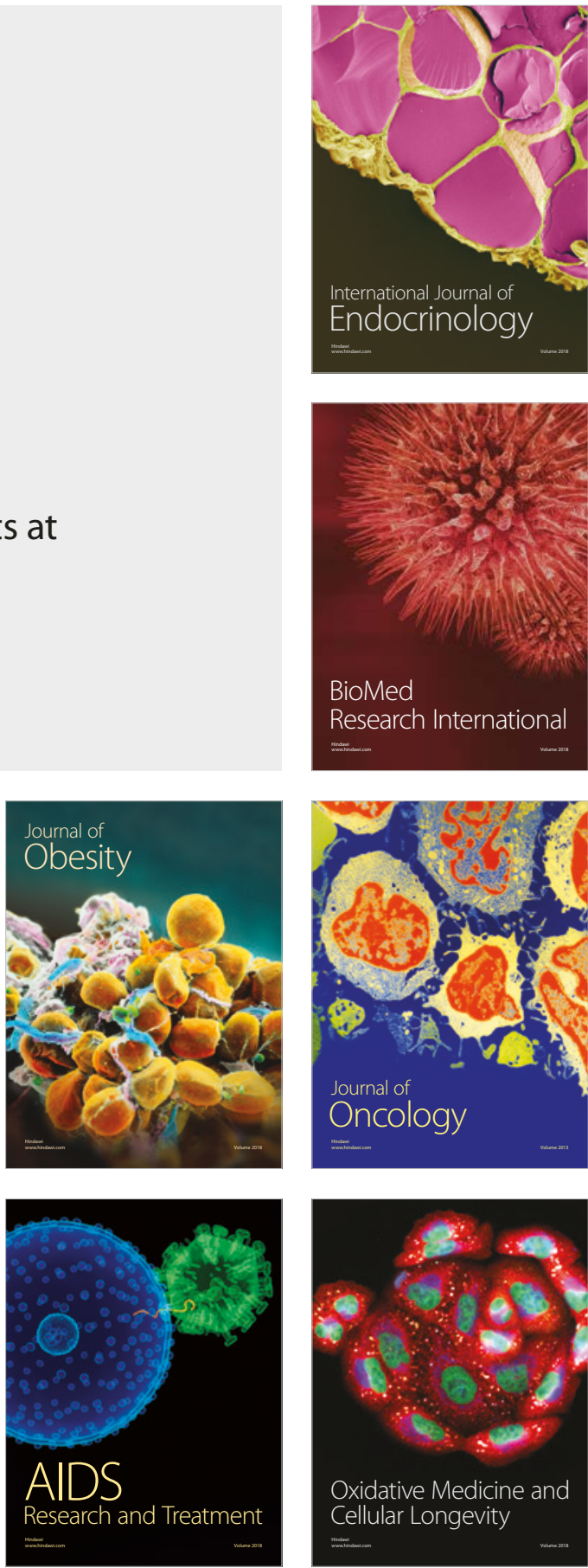